\title{
Bu open Male pattern baldness and its association with coronary heart disease: a meta-analysis
}

To cite: Yamada T, Hara $\mathrm{K}$, Umematsu $\mathrm{H}$, et al. Male pattern baldness and its association with coronary heart disease: a metaanalysis. BMJ Open 2013;3: e002537. doi:10.1136/ bmjopen-2012-002537

- Prepublication history and additional material for this paper are available online. To view these files please visit the journal online (http://dx.doi.org/10.1136/ bmjopen-2012-002537).

Received 28 December 2012 Revised 8 February 2013 Accepted 11 February 2013

This final article is available for use under the terms of the Creative Commons Attribution Non-Commercial 2.0 Licence; see http://bmjopen.bmj.com

Department of Diabetes and Metabolic Diseases, Graduate School of Medicine, University of Tokyo, Tokyo, Japan

Correspondence to Dr Kazuo Hara; haratky@gmail.com

\section{ABSTRACT}

Objective: To confirm the association between male pattern baldness and coronary heart disease (CHD).

Design: Meta-analysis of observational studies.

Data sources: Medline and the Cochrane Library were searched for articles published up to November 2012 using keywords that included both 'baldness' and 'coronary heart disease' and the reference lists of those studies identified were also searched.

Study selection: Observational studies were identified that reported risk estimates for $\mathrm{CHD}$ related to baldness. Two observers independently assessed eligibility, extracted data and assessed the possibility of bias.

Data synthesis: The adjusted relative risk (RR) and $95 \% \mathrm{Cl}$ were estimated using the DerSimonian-Laird random-effect model.

Results: 850 possible studies, 3 cohort studies and 3 case-control studies were selected (36990 participants). In the cohort studies, the adjusted RR of men with severe baldness for CHD was $1.32(95 \% \mathrm{Cl}$ 1.08 to $1.63, p=0.008, l^{2}=25 \%$ ) compared to those without baldness. Analysis of younger men $(<55$ or $\leq 60$ years) showed a similar association of $\mathrm{CHD}$ with severe baldness (RR $1.44,95 \% \mathrm{Cl} 1.11$ to 1.86 , $\mathrm{p}=0.006, \mathrm{I}^{2}=0 \%$ ). In three studies employing the modified Hamilton scale, vertex baldness was associated with $\mathrm{CHD}$ and the relation depended on the severity of baldness (severe vertex: RR 1.48 (1.04 to 2.11, $p=0.03$ ); moderate vertex: RR 1.36 (1.16 to $1.58, p<0.001$ ); mild vertex: RR 1.18 (1.04 to $1.35, p<0.001))$. However, frontal baldness was not associated with CHD (RR 1.11 (0.92 to $1.32, p=0.28)$ ).

Conclusions: Vertex baldness, but not frontal baldness, is associated with an increased risk of CHD. The association with $\mathrm{CHD}$ depends on the severity of vertex baldness and also exists among younger men. Thus, vertex baldness might be more closely related to atherosclerosis than frontal baldness, but the association between male pattern baldness and CHD deserves further investigation.

\section{INTRODUCTION}

Coronary heart disease (CHD) is a major cause of death and disability worldwide. ${ }^{1}$ Advanced obstructive CHD can exist in patients with minimal or no symptoms and

\section{ARTICLE SUMMARY}

\section{Article focus}

- The present meta-analysis aimed to confirm the association of male pattern baldness (androgenetic alopecia) with an increased risk of coronary heart disease (CHD).

\section{Key messages}

- Meta-analysis of six observational studies with a total of 36690 participants showed that vertex baldness is associated with an increased risk of $\mathrm{CHD}$ and that the relationship depends upon the severity of baldness, while frontal baldness is not.

- Thus, vertex baldness might be a marker of CHD and is more closely associated with systemic atherosclerosis than frontal baldness.

- This potential relationship should be investigated in further studies, including well-designed prospective studies.

Strengths and limitations of this study

- This was the first meta-analysis of the association between baldness and CHD; it showed that the relationship depends on the severity of baldness.

- The cohort studies had a long follow-up period of 11-14 years.

- A weakness might be the small number of studies analysed.

can progress rapidly, ${ }^{2}$ so early detection is extremely important. Many clinicians carry out screening for asymptomatic CHD and participants in well-being programmes often also request such screening, but the usefulness of CHD screening has yet to be confirmed. Young et $a l^{3}$ reported that the incidence of CHD was not significantly reduced in asymptomatic diabetic patients when screening was conducted by myocardial scintigraphy, and McEvoy et al also reported that coronary CT screening of asymptomatic patients without a history of coronary artery disease fails to prevent major cardiovascular events.

Male pattern baldness, also called androgenetic alopecia (AGA), is the most common 
cause of hair loss. It affects approximately $30-40 \%$ of adult men ${ }^{5}$ and is seen in $80 \%$ of men by the age of 80 years. ${ }^{6}$ AGA is considered to be a heritable, androgen-dependent condition that is characterised by varying degrees of thinning/hair loss primarily at the vertex and the frontal areas (temples) of the scalp. In men with AGA, the thin residual hairs tend to be of various lengths and diameters since each follicle is in a different phase of the hair cycle, so the presence of variations in hair length and texture is a classic feature of this thinning condition. ${ }^{7}$

Several recent studies have shown that baldness is associated with the risk of CHD. ${ }^{8-12}$ These studies have generally found a positive association between baldness and CHD, although the strength of the association has varied. $^{8-13}$

Clarifying the relationship between baldness and CHD could lead to more effective approaches to the early detection of heart disease, since it might permit the reliable identification of persons with an increased risk of suffering from a cardiac event, thereby allowing the delivery of appropriate therapy (eg, antihypertensive or lipid-lowering therapy) to improve the prognosis of such high-risk persons. Accordingly, we performed a meta-analysis to further assess the influence of male pattern baldness (AGA) on CHD.

\section{METHODS}

\section{Search strategy}

The MEDLINE and Cochrane Library electronic databases were searched from 1 January 1950 until 27 November 2012 using the medical subject headings 'Baldness' ('baldness' or 'hair loss' or 'alopecia') and 'Coronary heart disease' ('coronary heart disease' or 'cardiovascular disease' or 'coronary artery disease') to identify observational studies that estimated the association between baldness and CHD. The reference lists of all studies identified were also reviewed.

\section{Study selection}

We performed initial screening based on the study titles or abstracts, while the second screening involved a full-text review. Cohort studies, case-control studies and crosssectional studies that assessed the association between male pattern baldness and CHD were eligible for inclusion if the following criteria were met: (1) the full text of the report was published in English, (2) the relative risk (RR) (risk ratio, HR or OR) was reported with adjustment for possible covariates (eg, age, smoking, family history of baldness or family history of CHD), (3) the presence and severity of male pattern baldness was reported and (4) CHD events were reported.

\section{Definitions of baldness and CHD}

Baldness was defined according to the description in the history and/or on the basis of terms such as AGA and male pattern hair loss. We excluded studies that analysed men with other types of baldness (eg, alopecia areata or scarring alopecia). CHD was defined as including all of the following: coronary artery disease, myocardial infarction, angina pectoris, cardiomyopathy and other types of ischaemic heart disease.

\section{Assessment of validity}

To ascertain the validity of the eligible studies, the quality of each report was appraised with reference to the STROBE statement. ${ }^{14}$ Moreover, the Newcastle-Ottawa Scale for assessing the quality of non-randomised studies in meta-analyses was used to quantify the validity of each study. ${ }^{15}$

\section{Data extraction}

Two investigators (TY and $\mathrm{KH}$ ) independently reviewed each study to determine its eligibility, and then extracted and tabulated all of the relevant data. Disagreement was resolved by consensus between the two investigators.

The following information was obtained from each study: first author, year of publication, type of study, country where the study was conducted, number of participants (all participants who participated in the study), CHD events, method of assessing baldness, follow-up period, mean age, smoking, covariates used for adjustment during analysis and severity of baldness.

\section{Statistical analysis}

The pooled RR, adjusted for possible covariates, and its 95\% CI were calculated for the risk of CHD events in each study by the DerSimonian-Laird random effect model weighted with inverse variance. ${ }^{16}$ Equivalence of RRs between the cohort studies and the cross-sectional studies was assessed by the z-statistic test. Cochrane's $\chi^{2}$ test and the $\mathrm{I}^{2}$ test were used to evaluate heterogeneity among studies. ${ }^{17}$ Possible publication bias was evaluated by creating a funnel plot of the effect size for each study versus the SE. Funnel plot asymmetry was assessed by the Begg ${ }^{18}$ and Egger tests. ${ }^{19}$ All statistical analyses were performed with Stata V.12.0 software (StataCorp, College Station, Texas, USA). Results are expressed as the mean with $95 \%$ CI, unless otherwise indicated. A $p$ value of less than 0.05 was considered significant. All procedures were performed in accordance with the guideline published by the Meta-analysis Of Observational Studies in Epidemiology (MOOSE) group ${ }^{20}$ and the PRISMA statement ${ }^{21}$ (see online supplementary data 1 ).

\section{RESULTS}

\section{Literature search}

Figure 1 shows a flow chart of the study selection process. We identified a total of 850 reports by searching the databases. Among these, 834 reports were excluded after a review of the title and abstract, leaving 16 studies for further evaluation. Ten of these 16 studies were excluded after full text evaluation, chiefly because of the lack of pertinent data. The remaining six studies ${ }^{8-13}$ fulfilling the inclusion criteria were used for the present meta-analysis. 


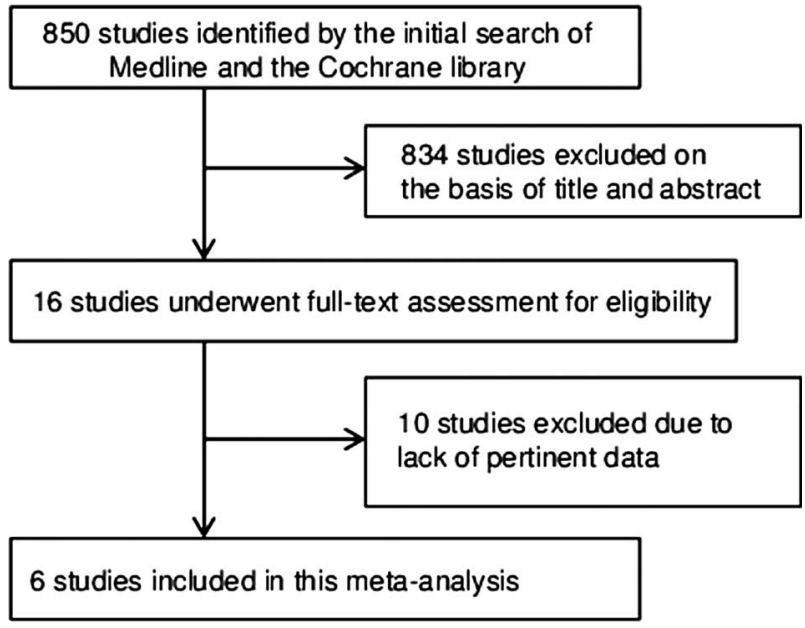

Figure 1 Flow diagram of study selection.

\section{Study characteristics}

The six studies that were selected included three cohort studies and three case-control studies, and their characteristics are summarised in table 1 . There were moderate differences with respect to the country, number of participants and method of assessing baldness. The studies were published between 1993 and 2008. Four studies ${ }^{9-11} 13$ were conducted in the USA and the other two ${ }^{8} 12$ were conducted in the European Union. The size of the study populations ranged from $1437^{11}$ to $19112^{10}$ participants (mean 6165 participants). In five of the six studies, ${ }^{8} 10-13$ CHD was defined as non-fatal myocardial infarction. The mean follow-up period ranged from 11 to 14 years. The method of assessing baldness varied, with a modified or simplified Hamilton scale being employed in four studies $^{8} \quad 1011 \quad 13$ and a personal scale being used in the other two studies. ${ }^{9} 12$

Three studies ${ }^{10} 11 \quad 13$ used a modified Hamilton scale that reduced the 12 categories of the original scale to the following five categories: no baldness (I and II); frontal alone (IIa, III, IIIa and IVa); mild vertex (III and IV); moderate vertex (V and Va) and severe vertex baldnesses (VI and VII). One study ${ }^{8}$ used a simplified Hamilton scale, in which the extent of baldness was classified as follows: none; frontoparietal region (no bald triangle but $>3 \mathrm{~cm}$ in front of the ear or bald triangle but $\leq 3 \mathrm{~cm}$ in front of the ear); crown-top region (thick hair, partly thin hair, bald spot or bald top and front) and combined.

Among the two studies that employed personal scales, Ford et al classified baldness as none, minimum, moderate or severe. Minimum baldness corresponded to no obvious baldness when the participant walked into the examining room, while moderate baldness was observable baldness at the first encounter and severe baldness was obvious at the first encounter. In the other study, Mirić et $a l^{12}$ classified baldness as none, frontal, parietal (vertex) or combined.

The RR for CHD of participants with baldness was adjusted for several coronary risk factors (age, smoking, diabetes, etc) in each study, but the number of variables differed significantly among the studies.

The reports on all three cross-sectional studies ${ }^{11-13}$ explicitly mentioned the limitations of a cross-sectional design (ie, it cannot assess causality), the possible biases of each study and the influence of covariates. The reports on all three cohort studies $^{8-10}$ mentioned the possibility of misclassification of the severity of baldness.

One study found that baldness was not associated with $\mathrm{CHD},{ }^{13}$ but the other five studies concluded that baldness was associated with a significantly increased risk of CHD, although the strength of the association varied.

According to the Newcastle-Ottawa quality assessment scale for observational studies, all the studies used in the present meta-analysis achieved at least six of nine points, indicating that the overall quality of the studies was good (see online supplementary data 2).

\section{Association of baldness with CHD}

Among the six studies with a total of 36990 participants that were selected, ${ }^{8-13}$ no study showed a significant decrease in the risk of CHD for men with baldness.

Figures 2-4 show the results obtained by combining the RRs for CHD with the random-effect model.

In the three cohort studies, ${ }^{8-10}$ the adjusted RR of CHD for men of all ages with severe baldness versus those without baldness was $1.32(95 \%$ CI 1.08 to 1.63 ; $\mathrm{p}=0.008$; $\mathrm{p}$ for heterogeneity $=0.26 ; \mathrm{I}^{2}=25 \%$ ) with non-significant heterogeneity. Analysis restricted to younger participants $(<55$ or $\leq 60$ years of age at baseline) revealed a similar association of severe baldness with CHD (RR 1.44 (95\% CI 1.11 to $1.86 ; \mathrm{p}=0.006$; $\mathrm{p}$ for heterogeneity $\left.=0.59 ; \mathrm{I}^{2}=0 \%\right)$ ) with non-significant heterogeneity ( figure 2 ).

In the three case-control studies, ${ }^{11-13}$ the adjusted RR was 1.70 (95\% CI 1.05 to $2.74 ; \mathrm{p}=0.03$; $\mathrm{p}$ for heterogeneity $=0.01: \mathrm{I}^{2}=78 \%$ ) for all participants, while the RR was $1.84(95 \%$ CI 1.30 to $2.62 ; \mathrm{p}=0.001 ; \mathrm{p}$ for heterogeneity $=0.17 ; \quad \mathrm{I}^{2}=44 \%$ ) among the younger participants (figure 3). The difference in RR values between the cohort and case-control studies was non-significant (all participants: $\mathrm{p}=0.15$; patients $\leq 60$ years old: $\mathrm{p}=0.07)$.

\section{Stratified analysis}

In the three studies that assessed the severity of baldness by using the modified Hamilton scale, ${ }^{10} \quad 11 \quad 13$ two studies ${ }^{10} 11$ showed that vertex baldness was associated with CHD and that this association was dependent on the severity of baldness. In participants with severe vertex baldness, the RR was 1.48 (95\% CI 1.04 to 2.11; $\mathrm{p}=0.03$; $\mathrm{p}$ for heterogeneity $\left.=0.02 ; \mathrm{I}^{2}=75 \%\right)$, while the RR was 1.36 (95\% CI 1.16 to 1.58 ; $\mathrm{p}<0.001$; p for heterogeneity $\left.=0.95 ; \mathrm{I}^{2}=0 \%\right)$ for moderate vertex baldness and 1.18 (95\% CI 1.04 to 1.35 ; $\mathrm{p}<0.001$; $\mathrm{p}$ for heterogeneity $=0.35$; $\mathrm{I}^{2}=4 \%$ ) for mild vertex baldness. In contrast, there was non-significant association of frontal baldness with CHD and the RR was only $1.11(95 \%$ CI 0.92 to $1.32 ; \mathrm{p}=0.28$; $\mathrm{p}$ for heterogeneity $=0.24 ; \mathrm{I}^{2}=30 \%$ ) (figure 4 ). 
Table 1 Summary of studies evaluating the association between baldness and coronary heart disease

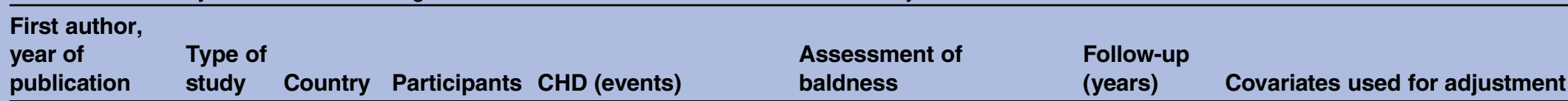

\begin{tabular}{|c|c|c|c|c|c|c|c|}
\hline Schnohr, $1995^{8}$ & Cohort & Denmark & 5837 & MI (524) & $\begin{array}{l}\text { Simplified Hamilton (none, } \\
\text { frontoparietal, crown-top, } \\
\text { combined) }\end{array}$ & 12 & $\begin{array}{l}\text { Age, smoking, systolic blood pressure, cholesterol, } \\
\text { triglycerides, physical activity, BMI, family history of } \\
\text { MI, marital status, education, economic status, } \\
\text { diabetes and alcohol consumption }\end{array}$ \\
\hline Ford, $1996^{9}$ & Cohort & $\begin{array}{l}\text { The } \\
\text { USA }\end{array}$ & 3994 & $\begin{array}{l}\text { Ischaemic heart } \\
\text { disease (965) }\end{array}$ & $\begin{array}{l}\text { Personal scale (none, } \\
\text { minimum, moderate, } \\
\text { severe) }\end{array}$ & 14 & $\begin{array}{l}\text { Age, age squared, race, education, systolic blood } \\
\text { pressure, antihypertensive medication, cholesterol, } \\
\text { smoking, BMI and diabetes mellitus }\end{array}$ \\
\hline Lotufo, $2000^{10}$ & Cohort & $\begin{array}{l}\text { The } \\
\text { USA }\end{array}$ & 19112 & $\begin{array}{l}\text { Non-fatal MI, angina, } \\
\text { coronary } \\
\text { revascularisation (1446) }\end{array}$ & $\begin{array}{l}\text { Modified Hamilton (none, } \\
\text { frontal, mild vertex, } \\
\text { moderate vertex, severe } \\
\text { vertex) }\end{array}$ & 11 & $\begin{array}{l}\text { Age, aspirin assignment, } \beta \text {-carotene assignment, } \\
\text { BMI, height }(\mathrm{cm}) \text {, hypertension, } \\
\text { hypercholesterolaemia, diabetes, parental history of } \\
\text { MI, physical activity, smoking and alcohol use }\end{array}$ \\
\hline Lesko, $1993^{11}$ & $\begin{array}{l}\text { Case- } \\
\text { control }\end{array}$ & $\begin{array}{l}\text { The } \\
\text { USA }\end{array}$ & 1437 & Non-fatal MI (665) & $\begin{array}{l}\text { Modified Hamilton (none, } \\
\text { frontal only, mild vertex, } \\
\text { moderate vertex, severe } \\
\text { vertex) }\end{array}$ & - & $\begin{array}{l}\text { Age, race, religion, years of education, BMI, use of } \\
\text { alcohol and cigarettes, family history of MI, } \\
\text { personal history of angina, hypertension, diabetes, } \\
\text { hypercholesterolaemia, gout, exercise, personality } \\
\text { and number of doctor visits in the past year }\end{array}$ \\
\hline Mirić, $1998^{12}$ & $\begin{array}{l}\text { Case- } \\
\text { control }\end{array}$ & Croatia & 1554 & Non-fatal MI (842) & $\begin{array}{l}\text { Personal score (none, } \\
\text { any, frontal, parietal, } \\
\text { frontoparietal) }\end{array}$ & - & $\begin{array}{l}\text { Age, family history of MI, hypertension, } \\
\text { hypercholesterolaemia, BMI, diabetes and smoking }\end{array}$ \\
\hline Shahar, $2008^{13}$ & $\begin{array}{l}\text { Case- } \\
\text { control }\end{array}$ & $\begin{array}{l}\text { The } \\
\text { USA }\end{array}$ & 5056 & Non-fatal MI (767) & $\begin{array}{l}\text { Modified Hamilton (none, } \\
\text { frontal, mild vertex, } \\
\text { moderate vertex, severe } \\
\text { vertex) }\end{array}$ & - & $\begin{array}{l}\text { Age, smoking, BMI, race-centre, } \\
\text { cholesterol-lowering medication, antihypertensive } \\
\text { medication, HDL, diabetes, educational level and } \\
\text { family history of MI }\end{array}$ \\
\hline
\end{tabular}

BMI, body mass index; $\mathrm{CHD}$, coronary heart disease; HDL, high-density lipoprotein;MI, myocardial infarction; 
Figure 2 Association of baldness with coronary heart disease (CHD) in the three cohort studies. The forest plot shows the association between male pattern $\mathrm{RR}$, relative risk. baldness and the risk of CHD.

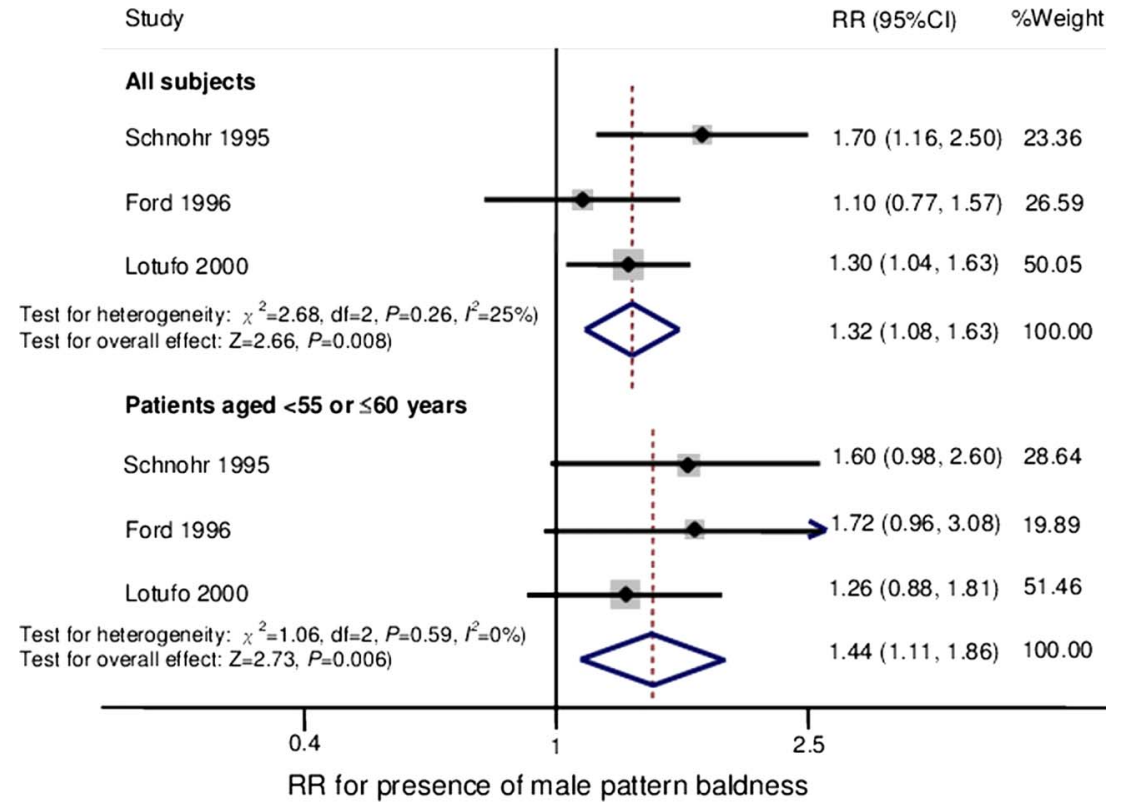

Because the method of assessing baldness was not homogeneous, we also performed a sensitivity analysis of the studies that used personal scales to classify baldness into four grades (none, frontal, crown-top or combined) ${ }^{8} 12$ Similar results were obtained showing that the association with CHD depended on the severity of baldness, with an RR of 1.69 (95\% CI 1.28 to 2.23; $\mathrm{p}<0.001 ; \mathrm{p}$ for heterogeneity $=0.97 ; \mathrm{I}^{2}=0 \%$ ) for combined baldness, an RR of 1.52 (95\% CI 0.97 to 2.39; $\mathrm{p}=0.07$; $\mathrm{p}$ for heterogeneity $=0.001 ; \mathrm{I}^{2}=91 \%$ ) for crown-top baldness and an RR of 1.22 (95\% CI 0.70 to 2.14; $\mathrm{p}=0.49$; $\mathrm{p}$ for heterogeneity $=0.05 ; \mathrm{I}^{2}=73 \%$ ) for frontal baldness.

\section{Publication bias}

The funnel plot, Begg's test and Egger's test were used to evaluate the potential influence of publication bias on the association between baldness and CHD. The funnel plot did not show an asymmetric pattern, while Egger's and Begg's tests revealed non-significant publication bias (all $\mathrm{p} \geq 0.05$ ).

\section{DISCUSSION}

The present meta-analysis of six studies from the USA and Europe demonstrated that vertex baldness was significantly associated with an increased risk of CHD among participants of all ages and also among younger men. Interestingly, frontal baldness was non-significantly associated with CHD. scale, which is the most commonly used classification of male pattern baldness worldwide, ${ }^{22}$ the relationship between CHD and baldness was shown to be dependent on the severity of baldness.
When baldness was classified by the Hamilton-Norwood
Figure 3 Association of baldness with coronary heart disease (CHD) in the three casecontrol studies. The forest plot shows the association between male pattern baldness and the risk of $\mathrm{CHD}$. RR, relative risk.

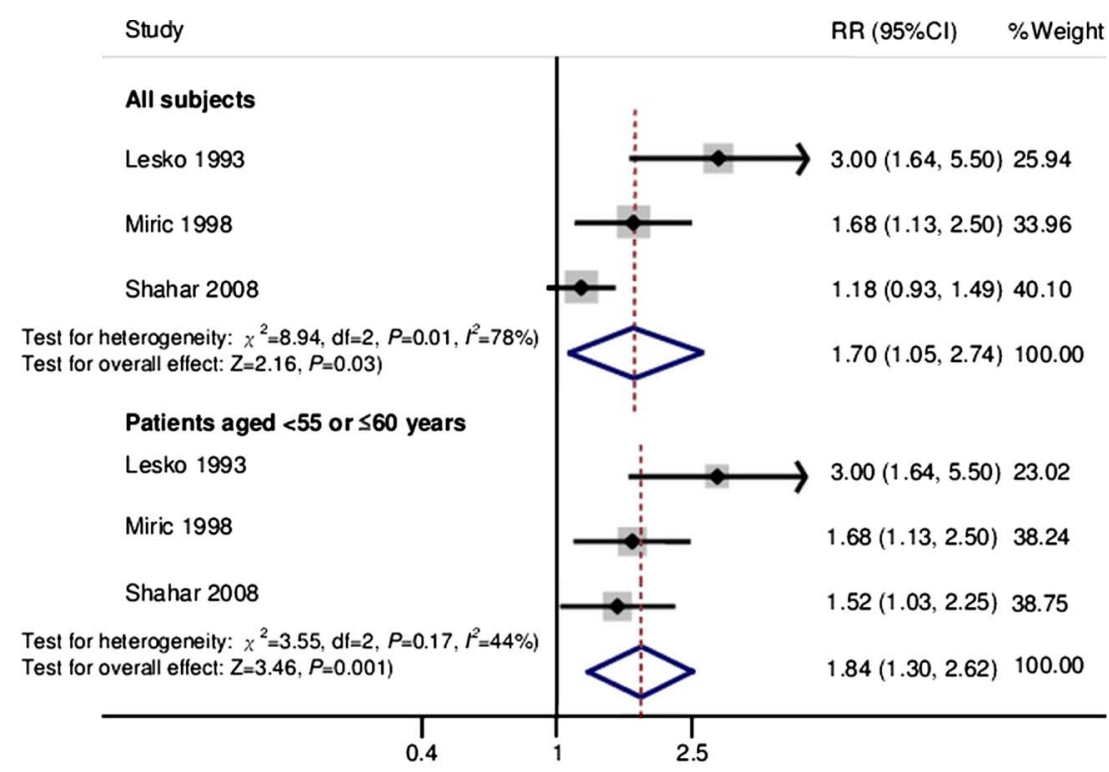

$\mathrm{RR}$ for presence of male pattern baldness 
Figure 4 Association of baldness with coronary heart disease (CHD) in studies using the modified Hamilton scale. The forest plot shows the association between male pattern baldness and the risk of $\mathrm{CHD}$. RR, relative risk.

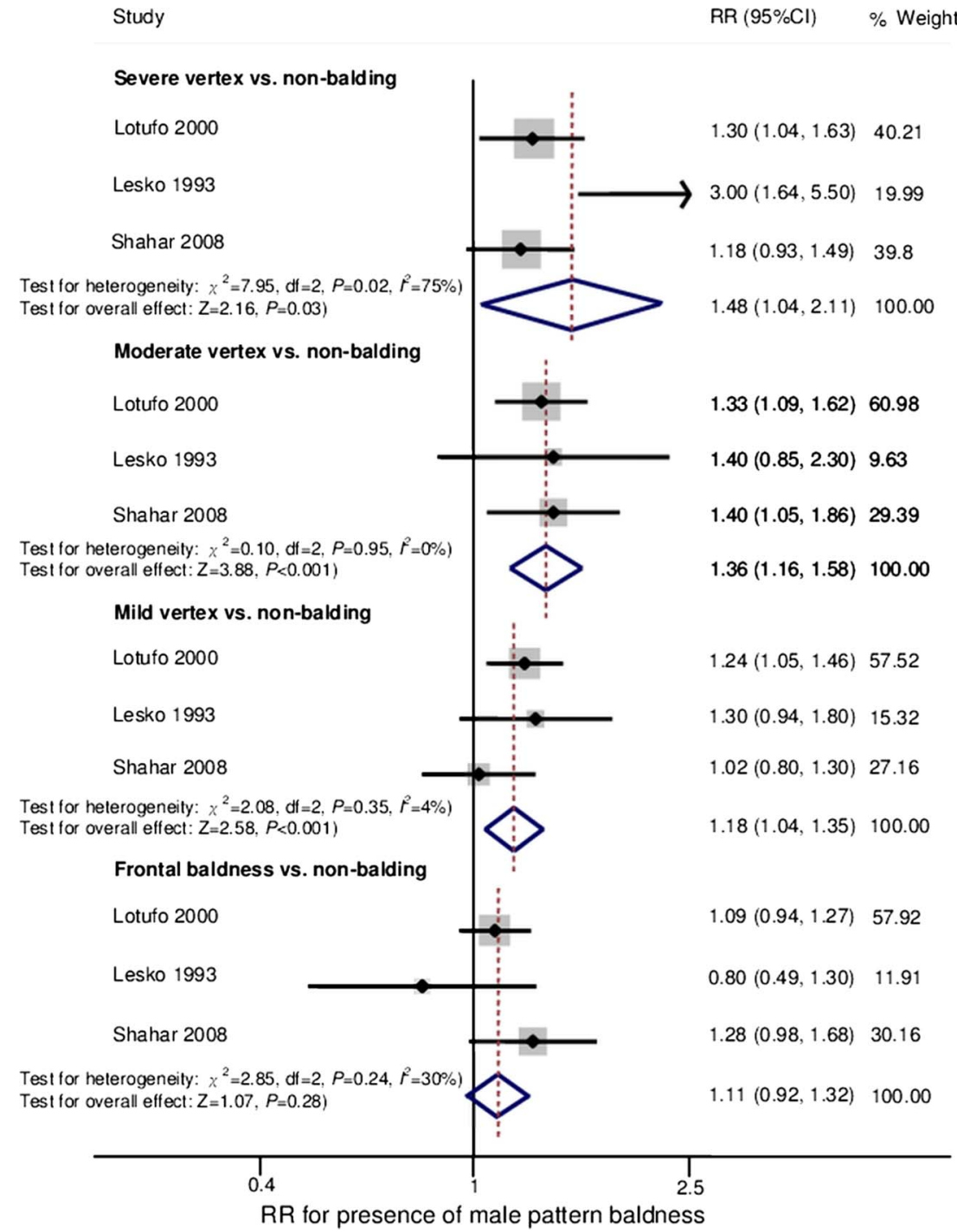

Our meta-analysis of young men alone also showed a significant relationship between AGA and the risk of CHD, similar to that revealed by the meta-analysis of men of all ages (figures 2 and 3). The results were consistent with those of many studies published so far, which have shown that early onset of AGA is related to a risk of early severe CHD and its risk factors. ${ }^{23-26}$

These findings support the hypothesis that vertex baldness is a local manifestation of factors promoting systemic atherosclerosis, such as metabolic syndrome, hypertension and smoking.

Minoxidil (Rogaine/Regaine) is one of the most popular drugs for the treatment of male pattern baldness. Minoxidil was originally developed as an antihypertensive agent (vasodilator). It is thought to improve the blood flow and the supply of oxygen and nutrients to the hair follicles by dilating vessels in the scalp and opening potassium channels. This might lead to the shedding of hairs in the telogen phase, which are then replaced by thicker hairs in the anagen phase. ${ }^{27}$
Minoxidil is only indicated for vertex baldness and is ineffective for frontal baldness, ${ }^{28}$ which supports our finding that vertex baldness is more closely related to atherosclerosis than frontal baldness.

\section{Mechanism of the relation between baldness and CHD}

The reason for the association between baldness and CHD is unclear. It has been suggested that classical coronary risk factors (eg, age, hypertension, dislipidaemia and smoking) might influence both conditions, so that baldness is a marker of atherosclerosis. In fact, previous studies have demonstrated a positive association between male pattern baldness and insulin resistance, ${ }^{23}$ metabolic syndrome ${ }^{29}$ and hypertension. ${ }^{30}$ It has also been postulated that baldness is linked to CHD by mechanisms such as hyperinsulinaemia, chronic inflammation and increased peripheral sensitivity to androgens, and these are briefly discussed below.

1. Hyperinsulinaemia/insulin resistance is the central factor in metabolic syndrome and it promotes 
intolerance of carbohydrates and the development of central (abdominal) obesity. Insulin resistance has also been shown to cause vasoconstriction and impair the supply of nutrients to the hair follicles of the scalp, as well as enhancing the influence of dihydrotestosterone (DHT) on follicular miniaturisation. ${ }^{24} 31$

2. A proinflammatory state could increase the levels of inflammatory cytokines in the arterial walls ${ }^{32}$ and hair follicles. ${ }^{25}$ High-sensitivity $\mathrm{C}$ reactive protein is a marker of inflammation and also a good predictor of future cardiovascular disease, ${ }^{33}$ so chronic inflammation could be related to both CHD and baldness.

3. Male pattern baldness might be caused by increased peripheral sensitivity to androgens, since bald men show an increase of androgen receptors in the scalp $^{34}$ and have higher serum levels of both total and free testosterone. ${ }^{35}$ Free testosterone is converted to DHT by 5a-reductase, leading to miniaturisation of hair follicles. It has been reported that 5a-reductase exists in the blood vessels and the heart, as does the DHT receptor, which is involved in vascular smooth muscle proliferation that represents a fundamental feature of atherosclerosis along with the deposition of lipids. ${ }^{36}$

\section{Strengths and limitations}

The strengths of the present meta-analysis were as follows. First, our analysis included several large cohort and case-control studies, with a total of 36990 participants. Second, the cohort studies had a long follow-up period (11-14 years). In all of the studies, analyses were adjusted for various classical coronary risk factors, such as age, smoking, hypertension, dyslipidaemia and body mass index.

However, the present meta-analysis also had several limitations. First, we reviewed only English language reports for inclusion in this meta-analysis and might possibly have overlooked some non-English literature, which could have led to selection bias. However, we also investigated all of the references in each study as far as possible. Also, our analyses of publication bias did not suggest that unpublished results had been missed, but they might have been underpowered due to the small effect sizes. Second, although most factors showed nonsignificant between-study heterogeneity, it was significant for some factors, suggesting that differences in epidemiological characteristics (eg, the rate of severe baldness or CHD) or different diagnostic criteria (for baldness and/or CHD) contributed to the heterogeneity to some extent.

Unlike the results of the other studies, the effect sizes reported by Lesko et $a l^{11}$ varied widely and even changed the sign when different patterns of baldness were compared (figure 4 ). This study had the lowest validity score (6/9 points on the Newcastle-Ottawa scale) among the six studies included in our meta-analysis (see online supplementary data 2). Lesko et al contacted the coronary care units of participating hospitals to identify potential participants with their first myocardial infarction and to obtain permission to conduct an interview. Thus, details about CHD were not obtained in this study, which might have led to bias and influenced the effect size.

Moreover, as already reported by Rebora, ${ }^{37}$ Lotufo et $a l^{10}$ relied on each patient's memory of a condition that had developed up to 40 years before, which might have led to recall bias. These two studies would have a higher risk of misclassification bias that could lead to underestimating the strength of the association between baldness and CHD, since it is often considered shameful to admit to the existence of baldness.

The third limitation was incomplete information about the use of medications such as anticoagulants, anticonvulsants, $\beta$-blockers, antidepressants and hormone replacement therapy, which might have contributed to baldness. ${ }^{38}$

Fourth, the methods used to assess baldness varied between studies, which meant that we could not rule out other local causes of diffuse hair loss (alopecia areata or non-scarring alopecia), as well as possible systemic causes (eg, thyroiditis, iron deficiency, ${ }^{39} 40$ trauma, excessive dieting or debilitating diseases).

Even with such limitations, the present meta-analysis provided useful evidence regarding the potential influence of baldness on CHD. Patients and physicians should consider the possibility that baldness is associated with an increased risk of CHD.

\section{CONCLUSIONS}

In the present meta-analysis, vertex baldness was significantly associated with an increased risk of CHD among younger men as well as among all participants, and the association was dependent on the severity of baldness. These findings suggest that vertex baldness is more closely associated with systemic atherosclerosis than with frontal baldness. Thus, cardiovascular risk factors should be reviewed carefully in men with vertex baldness, especially younger men, and they probably should be encouraged to improve their cardiovascular risk profile. However, the usefulness of CHD screening in asymptomatic populations is yet to be elucidated, so the screening method (eg, exercise ECG, coronary CT or scintigraphy) employed should be practicable in terms of its advantages/disadvantages and cost performance, and patients should be evaluated for eligibility before screening to avoid possible over-medicalisation since male pattern baldness affects $30-40 \%$ of adult men. ${ }^{5}$

In addition, the association between baldness and CHD should be investigated in further studies, including well-designed and controlled cohort studies, in order to confirm whether persons with male pattern baldness (especially severe vertex baldness) have an increased risk of CHD.

Contributors TY, KH, HU and TK conceived the idea of the study and were responsible for the design of the study. TY and $\mathrm{KH}$ were responsible for undertaking the data analysis and produced the tables and figures. TY and $\mathrm{KH}$ 
provided input into the data analysis. The initial draft of the manuscript was prepared by $\mathrm{TY}$ and $\mathrm{KH}$ and then circulated repeatedly among all authors for critical revision. TY was responsible for the acquisition of the data and TY, KH and TK contributed to the interpretation of the results. All authors read and approved the final manuscript.

Funding This research received no specific grant from any funding agency in the public, commercial or not-for-profit sectors.

Competing interests All authors have completed the Unified Competing Interest form at http://www.icmje.org/coi_disclosure.pdf (available on request from the corresponding author) and declare: no support from any organisation for the submitted work; no financial relationships with any organisations that might have an interest in the submitted work in the previous 3 years; no other relationships or activities that could appear to have influenced the submitted work.

Provenance and peer review Not commissioned; externally peer reviewed.

Data sharing statement No additional data are available.

\section{REFERENCES}

1. Lopez AD, Mathers CD, Ezzati M, et al. Global and regional burden of disease and risk factors, 2001: systematic analysis of population health data. Lancet 2006;367:1747-57.

2. Lerner DJ, Kannel WB. Patterns of coronary heart disease morbidity and mortality in the sexes: a 26-year follow-up of the Framingham population. Am Heart J 1986;111:383-90.

3. Young LH, Wackers FJ, Chyun DA, et al. DIAD Investigators. Cardiac outcomes after screening for asymptomatic coronary artery disease in patients with type 2 diabetes: the DIAD study: a randomized controlled trial. JAMA 2009;301:1547-55.

4. McEvoy JW, Blaha MJ, Nasir K, et al. Impact of coronary computed tomographic angiography results on patient and physician behavior in a low-risk population. Arch Intern Med 2011;171:1260-8.

5. Olsen EA. Androgenetic alopecia. In: Olsen EA, ed. Disorders of hair growth: diagnosis and treatment. New York, NY: McGraw-Hill, 1994:257-83.

6. Hamilton JB. Patterned loss of hair in man; types and incidence. Ann N Y Acad Sci 1951;53:708-28.

7. Price VH. Treatment of hair loss. N Engl J Med 1999;341:964-73.

8. Schnohr P, Lange P, Nyboe J, et al. Gray hair, baldness, and wrinkles in relation to myocardial infarction: the Copenhagen City Heart Study. Am Heart J 1995;130:1003-10.

9. Ford ES, Freedman DS, Byers T. Baldness and ischemic heart disease in a national sample of men. Am J Epidemiol 1996;143:651-7.

10. Lotufo PA, Chae CU, Ajani UA, et al. Male pattern baldness and coronary heart disease: the Physicians' Health Study. Arch Intern Med 2000;160:165-71.

11. Lesko SM, Rosenberg L, Shapiro S. A case-control study of baldness in relation to myocardial infarction in men. JAMA 1993;269:998-1003.

12. Mirić D, Fabijanić D, Giunio L, et al. Dermatological indicators of coronary risk: a case-control study. Int J Cardiol 1998;67:251-5.

13. Shahar E, Heiss G, Rosamond WD, et al. Baldness and myocardial infarction in men: the atherosclerosis risk in communities study. Am $J$ Epidemiol 2008;167:676-83.

14. Von Elm E, Altman DG, Egger M, et al. The Strengthening the Reporting of Observational Studies in Epidemiology (STROBE) statement: guidelines for reporting observational studies. J Clin Epidemiol 2008;61:344-9.

15. Wells G, Shea B, O'Connell D, et al. The Newcastle-Ottawa Scale (NOS) for assessing the quality of nonrandomised studies in meta-analyses [Internet]. Ottawa Hospital Research Institute. http:// www.ohri.ca/programs/clinical_epidemiology/oxford.asp (accessed 4 Dec 2012).

16. DerSimonian R, Laird N. Meta-analysis in clinical trials. Control Clin Trials 1986;7:177-88.
17. Higgins JP, Thompson SG. Quantifying heterogeneity in a meta-analysis. Stat Med 2002;21:1539-58.

18. Begg CB, Mazumdar M. Operating characteristics of a rank correlation test for publication bias. Biometrics 1994;50: 1088-101

19. Egger M, Davey Smith G, Schneider M, et al. Bias in meta-analysis detected by a simple, graphical test. BMJ 1997;315:629-34.

20. Stroup DF, Berlin JA, Morton SC, et al. Meta-analysis of observational studies in epidemiology: a proposal for reporting. Meta-analysis Of Observational Studies in Epidemiology (MOOSE) group. JAMA 2000;283:2008-12.

21. Liberati A, Altman DG, Tetzlaff J, et al. The PRISMA statement for reporting systematic reviews and meta-analyses of studies that evaluate health care interventions: explanation and elaboration. Ann Intern Med 2009;151:W65-94.

22. Norwood OT. Male pattern baldness: classification and incidence. South Med J 1975;68:1359-65.

23. Mumcuoglu C, Ekmekci TR, Ucak S. The investigation of insulin resistance and metabolic syndrome in male patients with early-onset androgenetic alopecia. Eur J Dermatol 2011;21:79-82.

24. Matilainen V, Koskela P, Keinänen-Kiukaanniemi S. Early androgenetic alopecia as a marker of insulin resistance. Lancet 2000;356:1165-6.

25. Hirsso P, Rajala U, Hiltunen L, et al. Obesity and low-grade inflammation among young Finnish men with early-onset alopecia. Dermatology 2007;214:125-9.

26. Matilainen VA, Mäkinen PK, Keinänen-Kiukaanniemi SM. Early onset of androgenetic alopecia associated with early severe coronary heart disease: a population-based, case-control study. J Cardiovasc Risk 2001;8:147-51.

27. Messenger AG, Rundegren J. Minoxidil: mechanisms of action on hair growth. Br J Dermatol 2004;150:186-94.

28. Scow DT, Nolte RS, Shaughnessy AF. Medical treatments for balding in men. Am Fam Physician 1999;59:2189-94.

29. Su LH, Chen TH. Association of androgenetic alopecia with metabolic syndrome in men: a community-based survey. $\mathrm{Br} J$ Dermatol 2010;163:371-7.

30. Ahouansou S, Le Toumelin P, Crickx B, et al. Association of androgenetic alopecia and hypertension. Eur J Dermatol 2007; 17:220-2.

31. Arias-Santiago S, Gutiérrez-Salmerón MT, Castellote-Caballero L, et al. Male androgenetic alopecia and cardiovascular risk factors: A case-control study. Actas Dermosifiliogr 2010;101:248-56.

32. Yudkin JS, Stehouwer CD, Emeis JJ, et al. C-reactive protein in healthy subjects: associations with obesity, insulin resistance, and endothelial dysfunction: a potential role for cytokines originating from adipose tissue? Arterioscler Thromb Vasc Biol 1999;19:972-8.

33. Ridker PM. Clinical application of C-reactive protein for cardiovascular disease detection and prevention. Circulation 2003;107:363-9.

34. Hibberts NA, Howell AE, Randall VA. Balding hair follicle dermal papilla cells contain higher levels of androgen receptors than those from non-balding scalp. J Endocrinol 1998;156:59-65.

35. Demark-Wahnefried W, Lesko SM, Conaway MR, et al. Serum androgens: associations with prostate cancer risk and hair patterning. J Androl 1997;18:495-500

36. Fujimoto R, Morimoto I, Morita E, et al. Androgen receptors 5alfa-reductase activity and androgen-dependent proliferation of vascular smooth muscle cells. J Steroid Biochem Mol Biol 1994;50:169-74.

37. Rebora A. Baldness and coronary artery disease: the dermatologic point of view of a controversial issue. Arch Dermatol 2001;137:943-7.

38. Llau ME, Viraben R, Montastruc JL. Drug-induced alopecia: review of the literature. Therapie 1995;50:145-50.

39. Trost LB, Bergfeld WF, Calogeras $\mathrm{E}$. The diagnosis and treatment of iron deficiency and its potential relationship to hair loss. J Am Acad Dermatol 2006;54:824-44.

40. Olsen EA. Iron deficiency and hair loss: the jury is still out. J Am Acad Dermatol 2006;54:903-6. 